\title{
The Influence Of Feedback Environment Towards Job Satisfaction In Tvet Education Organization
}

\author{
Ying-Leh Ling ${ }^{1}$, Zakir Hussain Bin Ibrahim ${ }^{2}$ \\ 1, 2 Politeknik Kuching Sarawak, Malaysia \\ e-mail: drylling@poliku.edu.my, zh.ibrahim@gmail.com
}

\begin{abstract}
This was a study descriptively identifying relationship between feedback environment and job satisfaction conducted in Polytechnic Malaysia. A total of 105 lecturers via random sampling method were chosen from local Technical and Vocational Education and Training (TVET) education organization in Sarawak. The questionnaire consisted of three parts including the modified items of Job Satisfaction Scale (Ling, 2016; Quinn \& Shepard, 1974). The extent of organization support on feedback process was diagnosed using feedback environment questionnaires by Ling (2016). The findings displayed that there is a significant influence in feedback environment towards job satisfaction. Regression analysis also showed that the best combination of feedback credibility, feedback quality and feedback delivery contributed greater change in job satisfaction. In conclusion, this study recommends that feedback environment factors should be prioritized not only to create job satisfaction but to maintain the effectiveness of the organization in the long run.
\end{abstract}

Keywords: Job satisfaction, feedback environment

\section{Introduction}

In the world of human resource management, employees are one of the greatest assets and job satisfaction in the workplace that should not be taken lightly. According to the Employee Job Satisfaction and Engagement Report by the Society for Human Resource Management, for the first time in several years, the number of employees who say they are satisfied with their current job took a big jump, rising from $81 \%$ in 2013 to $88 \%$ in 2016 . The term job satisfaction may be associated with unpleasant emotional condition that results from the evaluation of a person against his will in tune with what's going on in his job. When individual tries to find tranquillity with frequent drinking while working, surfing the internet for hours, chat with colleagues or late to work to be willing to show false illnesses to employers, these are indicators of individual work productivity has decreased because job satisfaction is not fulfilled (Nor Azzah, 2016). When job satisfaction has been met, integrity and work commitment can be realized (Gul, Usman, Liu, Rehman, \& Jebran, 2018). In other words, having a satisfied and happy workforce strengthens the organizations by lowering the employee turnover, increasing employees' productivity, increasing customer satisfaction and promoting loyalty. Furthermore, happy employees are more likely to help in transferring their knowledge and skills to others because they care about the well-being, as well as, the coworkers being left behind.

In the modern era, one of the many challenges is to satisfy the employees in order to cope up with the ever changing and progressing environment and to achieve success and remain in competition. Unfortunately, most organizations ignore the importance of feedback in the workplace resulting in an adverse effect on the performance of their employees. Feedback in the workplace includes the practices of giving and receiving the feedback as a powerful tool in the workplace. It informs employees about their performance and behaviour in the team. Accordingly, the study of Auh, Menguc, Imer, and Uslu (2018) has proven that the feedback environment can lead to an improvement in individual's achievement, productivity, and workplace satisfaction in a more satisfactory. In the context of education, the feedback environment was also positively correlated with self-efficacy of teaching (Ling, Abdul Ghani, \& Aziah, 2015) and student creativity (Ling, Fairuz, \& Abdul Ghani, 2015). Previous studies have shown that feedback environment has a high potential on the formation of highly skilled workers to produce high productivity. At the same time, high job satisfaction in the 
organization also determines the creation and retention of work commitments, performance and employee contributions. Hence, the researcher wants to identify whether the feedback environment in the TVET education organization specifically has the influence on job satisfaction so that constructive suggestions can be made to the management for further action. The aim of this study was to ascertain the relationship between job satisfaction and feedback environment in a TVET education organization. This study also discussed the influence of feedback environment on job satisfaction in the TVET education organization, especially among Malaysian polytechnic lecturers.

\section{Literature Review}

\section{Feedback Environment}

Feedback are information's with relations to work environment which will indicate how well a subordinate is performing. From a study conducted by Rosen, Levy \& Hall (2006), it was proven feedback environment as "an antecedent of perceptions of organizational politics". There is a relation on supervisor ratings of performance with organisational politics. Perceptions on politics and performance affects employee's morale. To attain a superior comprehension towards the assessment information progression in the relationship between the stakeholder and the evaluator, Azzam and Whyte (2018) argued that impacts of various components are considered particularly the type (favourable / unfavourable) and precision of the assessment and feedback conveyance procedures which includes the plausible validity, impact, and utility of feedback. The study conducted by Azzam and Whyte (2018) pinpoints three possible consequences on feedback delivery. These includes feedback's usefulness, influence and credibility. The finding from the study proves that positive feedback is "viewed as more credible, regardless of the delivery strategy". Responses from the participants of the study view the outcomes as dependable however the results do not impact them to be of any use. In other words, employees receiving positive feedback will not be influenced by the results towards their performance

Favourable feedback environment enhances subordinates' creativity (Davidson \& De Stobbelier, 2011). Davidson (2011) furthermore established correlation between feedback environment and creative performance. There are inconsistencies between Azzam's view and Davidson's concerning the results of their studies. Azzam's study shows that positive environment will not be influenced by the results. However, Davidson established that favourable feedback environment enhances subordinates' creativity.

Ling et al (2016) in research on feedback environment has identified six different facets in the context of Malaysia. The six facets identified are feedback credibility, feedback quality, feedback delivery, feedback availability, encourage feedback seeking and favourable feedback. His findings did not include facets of unfavourable feedback as identified by Steelman, Levy and Snell (2004) due to cultural differences being studied. In the same paper, Ling et al (2016) mentions the need to have feedback environment so as to encourage middle leaders to be motivated. With this, job satisfaction can be achieved. The paper was able to establish a relationship between job satisfaction and feedback environment. A motivated staff will be more productive and effective towards their organisation.

Feedback credibility relates to the trustworthiness and the proficiency of the feedback provider as perceived by the individuals (Bozer, Sarrosm \& Santora, 2014). Pornpitakpan (1997) describes the feedback from a high-credibility source appears to improve performance, especially when the message content is negative. High-credibility communicators induce more opinion change, compared with midly credible communicators. Finn et al. (2009) showed in her meta-analysis that teacher credibility positively affected student outcomes, such as motivation, learning and student's communication with teachers. In short, Monica Van de Ridder, Berk, Stokking, and Ten Cate (2015) indicates that feedback from high-credibility source is likely to alter performance. The second element of feedback environment is the content of feedback including feedback quality and constructive feedback. For feedback to be helpful, it should be accurate, specific, and constructive (Steelman et al., 2004). The relationship between effective feedback and job performance is well established (Sommer \& Kulkarni, 2012). By contrast, Nar Moon, \& Choi, 2015) found that there is no improvement in 
individual performance if the employee received low quality performance feedback from their supervisor. Constructive feedback should be a combination of praise and criticism regarding the performance of workers (Aguinis, Gottfredson, \& Joo, 2012). In other words, feedback provided should indicate areas of improvement in addition to giving recognition to good performance. The rationale of strength-based approach is to continuously develop the personal strengths of the employees rather than overcome their weaknesses (Buckingham \& Clifton, 2001).

There are seven facets of employee's perception evaluated individually. Firstly, source - source knowledge, reliability and competence; secondly, quality of feedback — consistency and usefulness of feedback; third, delivery of feedback - how considerate and tactful the feedback source is at the moment of delivery; fourth, favourable feedback - frequency of warranted favourable feedback (positive feedback such as praise or achievement feedback that correctly represents real excellent performance on the job) ; fifth, unfavourable feedback - frequency of warranted unfavourable feedback (adverse feedback such as accurate criticism); sixth, the availability of sources - the ease with which feedback is obtained from sources of feedback; and lastly, the extent to which feedback is promoted and encouraged by sources of feedback (Momotani \& Otsuka, 2018).

Previous research (Anseel \& Lievens, 2007) proved that the quality of exchange between leader and member completely mediated connection between supervisor feedback setting and job satisfaction, leading to beneficial long-term impact of the feedback setting on job satisfaction in a distinct cultural context. The consequences of the research indicates that due to cultural and societal dimensions, feedback processes also differ depending on the organisations. The perception of an employee (Rosen, Levy, \& Hall, 2006) of his / her supervisor's feedback setting was heavily linked to the quality of his / her supervisor relationship, which was linked to job satisfaction.

A closely relevant component to the feedback content is feedback delivery. In this study, feedback delivery refers to the process and methods of delivery feedback. Bear et al. (2017) argued that feedback is an evaluate procedure. The person who gives the feedback must deliver the feedback to the recipient discretely. Another influential factor of feedback environment is the availability of feedback. Halpern (2004) explained the availability of systematic and evaluative feedback is often hypothesized to be an essential input to the leadership development process. To a great extent, access to feedback can help individuals to deal with uncertainties (DeRue \& Wellman, 2009), which subsequently increase selfefficacy in handling challenging tasks. Access to feedback allows individuals to have better understanding of their competency and performance (Kluger \& DeNisi, 1996). On the contrary, the absence of feedback represents a developmental challenge. Broad and Goddard (2010) found that the absence of formal feedback reporting system in higher education institutions resulting a lack of accountability of the performing management system.

The last component of feedback environment is encouragement of feedback-seeking. Feedback seeking is a key component of informal learning process in the workplace (Tannenbaum, Beard, McNall, \& Salas, 2010). Feedback seeking has become a fundamental tool for professional development. It is a way to adapt and respond to the ever-changing goals and role expectations in current organizations. In this respect, it is a means to develop "knowhow" to improve human performance. Organization should create an approachable channel which allows their employees to seek feedback including the negative feedback from their supervisors. Proactive and self-regulatory subordinates seeking feedback creates a better relax communications with their supervisors as reported by Auh et al (2018). Thus, getting a better-quality information which shift ownerships responsibility to the subordinates leading to better performance, job satisfaction and improved productivity.

\section{Job Satisfaction}

Gul, Usman, Liu, Rehman, \& Jebran (2018) reported that the most authentic definition for job satisfaction was defined by Locke (1969) validating research done earlier by Abiyev, Saner, Eyupoglu, \& Sadikoglu (2016). Locke according to Gul et al., (2018), defined job satisfaction as "... a positive or pleasurable reaction resulting from the appraisal of one's job, 
job achievement, or job experiences". Trivellas, Reklitis and Platis (2013) quotes Locke (1969) defining job satisfaction as "the pleasurable emotional state resulting from the appraisal of one's job as achieving or facilitating the achievement of one's job values". Researchers have ascertained conflicting relationship between stress and job satisfaction. The stress is in relations to conflicts and heavy workload, where the studies done by Trivellas et al (2013) proves negative correlations with job satisfaction association. The job satisfaction dimensions including physical environment and career opportunities, management style and job enrichment, and rewards and job security. The instrument employed for this research was a modified instruments by Quinn \& Shepard (1974). They were using Pond III \& Geyer (1991), Farrell \& Rusbult (1981), and Rusbult \& Farrell (1983) for their job-satisfaction scale.

A positive feedback atmosphere as perceived by workers will encourage a worker to act favourably towards other co-worker. Interpersonal relationship and work performance increases job satisfaction in the workplace. A positive correlation between feedback environment and job satisfaction for both supervisor and co-worker (Momotani \& Otsuka, 2018). The importance of the feedback environment (Rosen et al., 2006) as an anterior of organizational policy perceptions has been demonstrated with empirical evidences that increase the focus of both feedback and political perception background. Organizational policy views were related both weakly and immediately to the scores of the supervisors. It should be observed that the efficiency has been multidimensional. Finding indicates that politics can perform an important part in critical organisational outcomes. Employee morality has been recognized as a mediator of the link between political attitudes and achievement as shown by assessments of work fulfilment and affective engagement, thus illustrating the fundamental processes related to work behaviour within organisational policy.

\section{Previous Research on Feedback Environment and Job Satisfaction}

Feedback can greatly influence organizational and work attitude. The benefits of feedback relate to both individuals and organizations; however, securing these benefits depends on the reaction of the feedback recipient. Satisfaction with feedback is an important dimension of the reaction of the feedback recipient (Keeping \& Levy, 2000).

Feedback delivery to employees is important to maintain and motivate and empower employees (Lam, Yik, \& Schaubroeck, 2002). Larson (1984) also describes giving feedback is one of the main rationales behind the formal assessment in the workplace. In other words, feedback satisfaction can determine the performance of employees; and indeed, future performance can be predicted more accurately based on satisfaction with feedback from based on the feedback itself (Anwar, Saif-Ur-Rehman, Mazen, \& Yasin, 2015). This is parallel to Bernardin and Beatty (1984), who suggest dissatisfaction with feedback can cause feedback to be ineffective in performance improvement.

Belschak and Hartog (2009) in their research tries to contend that affective reactions by employees towards feedback influences the conceptions of job performance at a broader scale. Their research tries to determine the consequences of receiving feedback from a feedback, either positive or negative; given within public or private context. According to Belschak et al (2009) feedbacks will cause reactions either at a cognitive level or an emotional level. At cognitive level, a feedback will increase comprehension and proficiency. A positive feedback will evoke a feeling of euphoria. A negative feedback evokes a feeling of discouragement.

The primary focus of the study by Belschak et al (2009) was to ensure when giving negative feedback, the supervisors or employers should be conscientious. Giving negative criticisms as a form of feedback may have significant advantage. Criticism can address problem, stimulate learning, and improve performance. They recommend that when giving criticism, it is better to construct it in a positive way rather than in a negative way. A constructive criticism will stimulate a positive effect.

Although negative feedback is unavoidable, supervisors should be aware that a negative feedback may elucidate a negative consequence. The negative consequence may be in the form of reduced motivation, reduced affective organisational commitment, and increased turnover intention. Therefore, supervisors with the intention of providing negative feedback 
should be vigilant of the circumstances as to elucidate emotional reactions which can be monitored and addressed.

\section{Research Method}

A survey was conducted for this study. The respondents consisted of 105 lecturers who taught at the polytechnic Malaysia. Profile of respondents were described using descriptive statistical analysis of gender, highest academic qualification, academic department, and duration of service. Random sampling method was employed in this study. The findings showed that the majority of respondents consisted of female lecturers with a total of 59 people, representing 56.2 percent. The analysis was performed on the highest academic qualification in which 53 lecturers have a bachelor's degree of representing 50.5 percent, while 43 lecturers or 41.0 percent have master's qualifications. In this regard, most respondents involved in this study were non-technical departments' lecturers with 59 people or 56.2 percent while 46 respondents were under the technical departments. The findings also showed that the majority of respondents have seven to ten years of working services in polytechnic (35.2 percent). Only 8 (7.6 percent) respondents served more than 10 years in polytechnics.

Table 1. Respondent profile $(\mathrm{N}=105)$

\begin{tabular}{llcc}
\hline \multicolumn{1}{c}{ Category } & \multicolumn{1}{c}{ Variable } & Frequency & Percentage \\
\hline Gender & Male & 46 & 43.8 \\
\multirow{3}{*}{ Academic Qualification } & Female & 59 & 56.2 \\
& Diploma & 1 & 1.0 \\
& Bachelor degree & 53 & 50.5 \\
& Master degree & 43 & 41.0 \\
Service Year & Doctorate degree & 8 & 7.6 \\
& & & \\
& Less than 3 years & 13 & 12.4 \\
Department & 3-6 years & 18 & 17.1 \\
& More than 10 years & 37 & 35.2 \\
& Technical & 8 & 7.6 \\
\hline
\end{tabular}

The instrument used was a questionnaire which was adapted from the feedback environment scale (Ling, 2016) and modified version of Quinn and Shepard's (1974) jobsatisfaction scale used by previous researchers. For feedback environment scale consisted of 25 items to diagnose the extent of organization support on feedback process. Global job satisfaction was measured with six items which was composed of the following items: (a) "If you had to decide all over again whether to take the job you now have, what would you decide?" (1-definitely not take job, 5-definitely take job); (b) "If a friend asked if he/she should apply for a job like yours with your employer, what would you recommend?" (1-recommend not at all, 5-recommend strongly); (c) "How does this job compare to your ideal job?" (1-very far from ideal, 5-very close to ideal); (d) "How does your job measure up to the sort of job you wanted when you took it?" (1-not at all like what I wanted, 5-just like what I wanted); "All things considered, how satisfied are you with your current job?" ( $1=$ not at all satisfied, $5=$ completely satisfied); and (f) "In general, how much do you like your job?" (1 = not at all, 5 = a great deal). A mean of the six items on this scale served as a job satisfaction score for each employee. Low and high scores represented low and high levels of job satisfaction, respectively. For job satisfaction, the mean score 4.80 which considered low level. Feedback environment overall mean score as high as 5.10 of a scale of 1 to 7 , which is moderate. 
Table 2. Mean score and standard deviation $(\mathrm{N}=105)$

\begin{tabular}{lcccccc}
\hline \multicolumn{1}{c}{ Variable } & Low & Moderate & High & Mean & S.D. & Level \\
\hline Feedback credibility & 32 & 19 & 54 & 5.18 & 1.514 & Moderate \\
& 30.5 & 18.1 & 51.4 & & & \\
Feedback quality & 29 & 16 & 60 & 5.14 & 1.283 & Moderate \\
& 27.6 & 15.2 & 57.1 & & & \\
Feedback delivery & 39 & 21 & 45 & 5.31 & 1.347 & Moderate \\
& 37.1 & 20.0 & 42.9 & & & \\
Feedback availability & 44 & 16 & 45 & 5.13 & 1.057 & Moderate \\
& 41.9 & 15.2 & 42.9 & & & \\
Positive feedback & 48 & 16 & 41 & 5.06 & 1.308 & Moderate \\
Encourage feedback seeking & 45.7 & 15.2 & 39.0 & & & \\
& 47 & 19 & 39 & 4.78 & 1.525 & Low \\
Job satisfaction & 44.8 & 18.1 & 37.1 & & & \\
& 47 & 11 & 47 & 4.80 & 1.486 & Low \\
\hline
\end{tabular}

\section{Research Findings and Discussion}

Multiple regression analysis was used to measure the contributions or responses of feedback environment on job satisfaction. The results of the data analysis showed that three of the six predictor variables: feedback credibility, feedback quality, and feedback delivery were included in the regression model at $p<.05$. The correlation between variable criterion (job satisfaction) and predictor variable (feedback credibility) is .574 while the correlation between variable criterion and linear combination between feedback credibility and feedback quality with variable criterion is .515. Next, Model 3 shows the correlation between variable criterion and linear combination between feedback credibility, feedback quality and feedback delivery are .548. The value of $\mathrm{R}^{2}$ in Model 1 showed 22.4 percent change in the criterion variable (job satisfaction) is caused by changes in feedback credibility. The combination of feedback credibility and feedback quality predicts 26.5 percent, which is approximately 4.0 percent of the variance of additional variance in variable job satisfaction criterion. In Model 3 , the value of $R^{2}=.301$ shows a 30.1 percent change in variable criterion (job satisfaction) is caused by changes in predictors variable feedback credibility, feedback quality, and feedback delivery, which is an additional 4.0 percent variance change in variable job satisfaction criterion. The ANOVA test results showed that there was a significant correlation between the two criterion variables and the predictor variables at the significance level $p<.05$. For Model 1 , the test results were significant $[F(1,103)=29.8, p<.05]$ while Model 2 findings showed that the test results were significant $[F(2,102)=18.4, p<.05]$. For Model 3 , ANOVA test results also show significant findings $[\mathrm{F}(3,101)=14.5, p<.05]$.

Feedback has been widely recognized as one of the factors that is very relevant to the performance appraisal process significantly on individuals or organizations (Jawahar, 2010). In general, feedback allows employees to become more aware of job performance as it has a positive and significant relationship with learning, motivation, job satisfaction, and work commitment (Ozturk, Hancer, \& Im, 2014). The findings of the study specifically are consistent with statements from Gordon and Miller (2011) where the best feedback comes from a reliable source who knows what he or she is talking about. This finding is supported by Steelman et al. (2004) where the quality of feedback provided to the employees is positively on the level of job satisfaction. Given the satisfaction of performance feedback recipients having an impact on self-efficacy in the work performed, the management should focus on the quality of feedback in the organization. 
Table 3. The standardized regression coefficient of the predictor variables

\begin{tabular}{lccc}
\hline \multirow{2}{*}{ Dependent variable } & \multicolumn{3}{c}{ Independent variable: Job Satisfaction } \\
\cline { 2 - 4 } & Model 1 $(\boldsymbol{\beta})$ & Model 2 $(\boldsymbol{\beta})$ & Model 3 $(\boldsymbol{\beta})$ \\
\hline Feedback credibility & $.47^{*}$ & .13 & .02 \\
Feedback quality & & $.40^{*}$ & .31 \\
Feedback delivery & & & $.28^{\star}$ \\
\hline R value & .474 & .515 & .548 \\
$\mathrm{R}^{2}$ value & .224 & .265 & .301 \\
Adjusted $\mathrm{R}^{2}$ value & .217 & .250 & .280 \\
F value & $29.8^{*}$ & $18.4^{*}$ & $14.5^{\star}$ \\
Durbin Watson & & 1.75 & \\
\hline
\end{tabular}

Note: Sig. at $p<.05$

\section{Implications and Conclusion}

The findings have shown that feedback environment has influence on job satisfaction, especially feedback credibility, feedback quality and feedback delivery (Sparr \& Sonnentag, 2008). Thus, the research of this paper gives impact towards the theoretical and the practical implication on job satisfaction in the workplace. The theoretical implication illustrates the three important aspect of job satisfaction; feedback credibility, feedback quality and feedback delivery. The practical aspect from the theoretical implication gives any organisation the best approach to maintain job satisfaction in a workplace. Therefore, the recommendation for future research apart from looking into feedback credibility, feedback delivery or feedback quality must include the frequency of giving feedback and the immediacy of feedback. These two elements, frequency and immediacy, may impact job satisfaction the effectiveness of an organisation in the long run.

A strong feedback environment should be researched upon, catering to distinct staff characteristics would be beneficial. Staff who are highly feedback-oriented might perform better in favourable feedback climate workplace, examine the importance and development of a favourable feedback setting by particular organizational actions. Manager activities in the implementation that should be influential in creating an atmosphere for supporting feedback. Future studies could study the effect on managers who have been trained on the feedback setting. It would be an exciting potential research on these feedback setting where a "360degree input" being implemented. The significance of an open exchange of data among staff, co-workers and managers, therefore may lead to a more positive feedback setting, typically highlights multifaceted feedback.

\section{References}

Abiyev, R.H., Saner, T., Eyupoglu, S., \& Sadikoglu, G. (2016). Measurement of job satisfaction using fuzzy sets. Procedia Computer Science, 102, $294-301$. https://doi:10.1016/j.procs.2016.09.404

Anseel, F., \& Lievens, F. (2007). The Long-Term Impact of the Feedback Environment on Job Satisfaction: A Field Study in a Belgian Context. Applied Psychology, 56(2), 254-266. https://doi.org/10.1111/j.1464-0597.2006.00253.x

Anwar, R., Saif-Ur-Rehman Khan, Mazen F. R., Yasin, M. (2015). The impact of feedback orientation and the effect of satisfaction with feedback on in-role job performance. Human Resource Development Quarterly, 26(1), 31-51. doi: 10.002/hrdq.21202

Auh, S., Menguc, B., Imer, P., \& Uslu, A. (2018). Frontline employee feedback-seeking behavior. Journal of Service Research, 1-16. doi:10.1177/1094670518779462

Azzam, T., \& Whyte, C.E. (2018), Evaluative feedback delivery and the factors that affect success. Evaluation and Program Planning, 67, 148-159. https://doi.org/10.1016/j.evalprogplan.2017.11.005

Bear, J. B., Cushenbery, L., London, M., \& Sherman, G. D. (2017), Performance feedback, power retention, and the gender gap in leadership. The Leadership Quarterly, 28(6), 721-740. http://dx.doi.org/10.1016/j.leaqua.2017.02.003 
Belschak, F. D., \& Den Hartog, D. N. (2009), Consequences of positive and negative feedback: The impact on emotions and extra-role behaviors. Applied Psychology, 58(2), 274-303. https:// doi: 10.1111/j.1464-0597.2008.00336.x

Bernardin, H. J., \& Beatty, R. W. (1984). Performance appraisal: Assessing human behaviour at work. Boston, MA: Kent.

Carpentier, J., \& Mageau, G. A. (2013). When change-oriented feedback enhances motivation, well-being and performance: A look at autonomy-supportive feedback in sport. Psychology of Sport and Exercise, 14(3), 423-435. https://doi.org/10.1016/j.psychsport.2013.01.003

Dahling, J. J., Gabriel, A. S., \& MacGowan, R. (2017), Understanding typologies of feedback environment perceptions: A latent profile investigation. Journal of Vocational Behavior, 101, 133-148. https://doi.org/10.1016/j.jvb.2017.05.007

Davidson, T., \& De Stobbeleir, K. (2011). The power of the feedback environment in stimulating creative performance: the role of task autonomy and self-concordance. Vlerick Leuven Gent Management School.

D'Lima, D., Arnold, G., Brett, S. J., Bottle, A., Smith, A., \& Benn, J. (2017). Continuous monitoring and feedback of quality of recovery indicators for anaesthetists: A qualitative investigation of reported effects on professional behaviour. British Journal of Anaesthesia, 119(1), 115-124. https://doi.org/10.1093/bja/aex136

Gordon, M. E., \& Miller, V. (2011). Conversations about job performance: A communication perspective on the appraisal process. New York, NY: Business Expert Press. https://doi:10.4128/9781606490754

Halpern, D. F. (2004). The development of adult cognition: Understanding constancy and change in adult learning. In D. A. Day, S. J. Zaccaro, \& S. M. Halpin (Eds.), Leader development for transforming organizations (pp. 125-152). Mahwah, NJ: Erlbaum.

Islami, X., Mulollia, E., \& Mustafa, N. (2018), Using management by objectives as a performance appraisal tool for employee satisfaction. Future Business Journal, 4(1), 94108. https://doi.org/10.1016/j.fbj.2018.01.001

Jawahar, I. M. (2010). The mediating role of appraisal feedback reactions on the relationship between rater feedback-related behaviors and rater performance. Group and Organization Management, 35(4), 494-526.

Kaymaz, K. (2011). Performance feedback: Individual based reflections and the effect on motivation. Business and Economics Research Journal, 2(4), 115-134.

Keeping, L. M., \& Levy, E. (2000). Performance appraisal reactions: Measurement, modeling and method bias. Journal of Applied Psychology, 85(5), 708-723. doi: 10.1037/00219010.85.5.708

Lam, S. S. K., Yik, M. S. M., \& Schaubroeck, J. (2002). Responses to formal performance appraisal feedback: The role of negative affectivity. Journal of Applied Psychology, 87, 192-201.

Ling, Y.L., Abdullah, A.G.K. \& Ismail, F. (2016). Feedback environment and job motivation among the middle leaders of educational organizations. Journal of Education and Training, 3(1), 90-105.

Momotani, H., \& Otsuka, Y. (2018). Reliability and validity of the Japanese version of the Feedback Environment Scale (FES-J) for workers. Industrial Health.

Mornica van de Ridder, J. M., Berk, F. C. J., Stokking, K. M., \& ten Cate, O. T. J. (2015). Feedback providers' credibility impacts students' satisfaction with feedback and delayed performance. Medical Teacher, 37(8), 767-774. doi. 10.3109/0142159X.2014.970617

Ozturk, A. B., Hancer, M., \& Im, J. Y. (2014). Job characteristics, job satisfaction, and organizational commitment for hotel workers in Turkey. Journal of Hospitality Marketing and Management, 23 (3), 294-313.

Rosen, C. C., Levy, P. E., \& Hall, R. J. (2006). Placing perceptions of politics in the context of the feedback environment, employee attitudes, and job performance. Journal of Applied Psychology, 91(1), 211-220.

Pornpitakpan, C. (2004). The persuasiveness of source credibility: A critical review of five decades' evidence. Journal of Applied Psychology, 34, 243-281. 
Steelman, L. A., Levy, P. E., \& Snell, A. F. (2004), The feedback environment scale: Construct definition, measurement, and validation. Educational and Psychological Measurement, 64(1), 165-184. https://doi.org/10.1177/0013164403258440

Tannenbaum, S. I., Beard, R. L., McNall, L. A., \& Salas, E. (2010). Informal learning and development in organizations. In S. W. J. Kozlowski \& E. Salas (Eds.), Learning, training and development in organizations (pp. 303-331). New York, NY: Routledge Taylor \& Francis Group.

Trivellas, P., Reklitis, P., \& Platis, C. (2013). The effect of job related stress on employees' satisfaction: A survey in health care. Procedia-Social and Behavioral Sciences, 73, 718726. 